\title{
Allometric Variation in Modern Humans and the Relationship Between Body Proportions and Elite Athletic Success
}

\author{
Tesla A. Monson ${ }^{1,2}$, Marianne F. Brasil ${ }^{1,2}$, Leslea J. Hlusko ${ }^{1,2}$ \\ ${ }^{1}$ Human Evolution Research Center, University of California, Berkeley, CA, ${ }^{2}$ Department of Integrative Biology, University of California, Berkeley, CA
}

\begin{abstract}
In many sports, greater height and arm span are purportedly linked to athletic success. While variation in body proportions has been explored across an array of scientific disciplines, studies focusing on humans of tall stature outside of clinical cases are limited. We investigated body size proportions in a sample of elite athletes, employing data on recruits for the National Basketball Association (NBA, $n=2,990$ ), mixed martial arts (MMA) fighters (mixedsex, $n=1,284$ ), as well as a control sample of healthy young adults who are not professional athletes, represented here by male $(n=4,082)$ and female $(n=1,986)$ recruits for the United States Army, to test two hypotheses: 1$)$ There is a significant difference in arm span to height ratios between elite professional athletes and the control population, and 2) There is a significant relationship between arm span to height ratio and athletic success within the NBA and MMA. We find that NBA players are significantly taller, with absolutely and relatively wider arm spans than MMA fighters and the control population. Additionally, we find that basketball players are significantly more likely to be drafted earlier in the NBA, and MMA fighters are significantly more likely to have a better loss to win ratio, if their arm span to height ratio falls above the regression line. However, we note that arm span and height, as well as athletic success, are impacted by a myriad of factors, and some of the most successful professional athletes do not have particularly long arms relative to their height.
\end{abstract}

Key words: Arm Span, Height, Body Size, Basketball, Mixed Martial Arts, Stature

\section{Introduction}

Human cultures have long celebrated athletic prowess, holding those who excel at feats of athleticism in high regard (Miller, 2005). Alongside this fascination has been a debate as to whether particular body shapes confer an advantage for different types of sports and/or provide an important marker for identifying potential success (Torres-Unda et al., 2013). Children today are often encouraged to participate in sports according to predisposed abilities perceived from their body shape (Sellers \& Kuperminc, 1997). For example, in the United States many tall statured young people are channeled into athletics, particularly basketball, often with the goal of professional employment and a profitable career (Beamon \& Bell, 2002; Sellers \& Kuperminc, 1997). This practice may explain, in part, why modern athletes are on average taller than athletes were 50-100 years ago (Norton \& Olds, 2001). In addition to height, a wide arm span (also referred to as wingspan or reach) has been considered important to athletic success (McCauley, 2018).

This focus on height and arm span raises questions about the interrelationship between them. The vast majority of research into human body proportions has focused on skeletal disorders and pathologies (Nwosu \& Lee, 2008; Rappold et al., 2007). There has been substantial medical research on individuals of particularly short stature, defined as being more than two standard deviations below the average (Shea \& Bailey, 1996), focused on individuals with skeletal and developmental abnormalities (Nwosu \& Lee,

\section{Correspondence:}

Montenegro T. Monson

Gport University of California Berkeley, Department of Integrative Biology, 3040 VLSB \#3140, Berkeley, CA 94706, United States E-mail: tesla.monson@berkeley.edu 
2008; Rappold et al., 2007). However, the number of investigations into typical variation in limb proportions among people of particularly tall stature are few and far between, and are overwhelmingly focused on pathological height (Davies \& Cheetham, 2014).

As for studies exploring the relationship between athletic success and body proportions, early research was largely bogged down by a preoccupation with ethnic and racial variation (Cureton \& Hunsicker, 1941). Most recent studies focus exclusively on variation in standard body size measurements and their association with 'positions' within an athletic team (a center in basketball, for example) or success at particular sports (Ackland et al., 1997; Torres-Unda et al., 2013) without discussion of relative proportions or allometric variation and their potential effects on overall athletic success. Many of these studies have also been hindered by small sample sizes.

To address these two gaps in the literature, we compiled a large dataset of publicly available body size measurements for two groups of elite athletes competing primarily in the United States: basketball players scouted by the National Basketball Association (NBA) and mixed martial arts (MMA) fighters. These groups of athletes compete in sports where a wide arm span is highly valued, and they represent team sports (basketball) and individual sports (mixed martial arts). We compared these professional athletes to a control population of US Army recruits to test two hypotheses: 1) professional athletes have larger arm span to height ratios compared to the control population; 2) success among professional athletes within the NBA and MMA correlates with a larger arm span to height ratio.

\section{Methods}

\section{Materials}

Our sample includes $n=2,990$ elite male basketball players scouted for the National Basketball Association (NBA) and $\mathrm{n}=1,284$ professional athletes (mixed sex) competing in mixed martial arts. We downloaded these data from the professional sports websites Draft Express (draftexpress.com) and Fight Metric (fightmetric.com). As a control population, we included data from $n=6,068$ United States Army recruits, measured as part of the ANSUR II (2012) Anthropometric Survey of US Army Personnel (Gordon et al., 2014). The sample of army recruits includes data for both males $(n=4,082)$ and females $(n=1,986)$, and represents the wide range of racial and ethnic backgrounds from which the United States military draws recruits. In total, the sample size is $\mathrm{n}=10,342$.

Previous studies on smaller samples of humans have found significant differences in height, and arm span to height ratio, between males and females (Nadankutty et al., 2014). Therefore, we analyzed the US Army recruits separately by sex. Sex-specific data were not available for the MMA athletes and the basketball data only include males.

The body size of both groups of athletes and the USA recruits was measured by medical staff when they were scouted or drafted into the professional leagues, or enlisted in the army, respectively. We focused on two body size traits. We included height (stature) and arm span for all three groups. Arm span is measured from fingertips to fingertips when the arms are extended laterally and held parallel to the ground (Gordon et al., 2014).

In order to assess the relationship between athletic success and body size proportions in NBA players and MMA fighters, we generated a metric of athletic success for each group (Table 1). For NBA players, the draft pick was used as a measure of athletic success leading up to entry into the profession $(n=731)$. For MMA fighters, the loss to win ratio was calculated and used as a measure of athletic success $(n=1,283)$, where a lower number indicates greater success. Using the loss to win ratio mathematically ensures that the athlete will have won at least one match in their career, and permits inclusion of athletes who have never lost a fight. The MMA loss to win ratio allows for a more direct indication of athletic success than does NBA draft number, but given that basketball is a team sport, the draft pick provides one of the only individualized numerical assessments in a basketball player's career. However, draft pick is likely influenced in part by an athlete's measured arm span, and results need to be considered with that caveat in mind. Both the draft pick and loss to win ratio were log-transformed to account for non-normal distribution of data.

Table 1. Mean athletic success by group

\begin{tabular}{lccc}
\hline Group & $\mathbf{N}$ & Statistic & Mean \\
\hline NBA & 731 & Draft pick & 28.71 \\
& & LogDraft & 1.32 \\
MMA & 1,283 & Losses & 5.21 \\
& & Wins & 14.60 \\
& & LWR & 0.37 \\
& & LogLWR & -0.45 \\
\hline
\end{tabular}

Note. Abbreviations as follows: NBA is National Basketball Association, MMA is mixed martial arts, $\mathrm{N}$ is sample size, LogDraft is the log-transformed draft pick, LWR is loss to win ratio, LogLWR is log-transformed loss to win ratio. Note that statistics of athletic success are not available for the full sample.

\section{Statistical analysis}

All statistical analyses were conducted in $\mathrm{R}$ Statistical Environment version 3.2.3 (R Core Team, 2015). We generated descriptive statistics of the traits using the summary and describe functions in the psych package (Revelle, 2015), and we calculated coefficient of variation using default mathematical language in $\mathrm{R}$ ( $\mathrm{R}$ Core Team, 2015). We ran a one-way MANOVA to compare the sample phenotypes across groups using the manova function. We calculated correlation coefficients between arm span and height using the rcorr function in the Hmisc package (Harrell \& Dupont, 2012). In order to compare traits of interest, we conducted a linear regression using the $\mathrm{lm}$ function for each group separately and as a combined sample, producing coefficients of determination $\left(\mathrm{R}^{2}\right)$, as well as slope equations for each group. Additionally, we applied an ANCOVA to test for the effect of height on arm span and compare linear regression lines across the groups. All bivariate plots were produced using the ggplot function in the ggplot2 package (Wickham, 2009). 


\section{Results}

Basketball players scouted for the NBA have the longest arm span, the greatest height, and the largest arm span to height ratio of the four groups sampled for this study (Table 2). On the other end of the spectrum, female Army recruits are shorter and have a shorter arm span and smaller arm span to height ratio than male recruits, MMA fighters (mixed-sex), and basketball players. Height and arm span are significantly different across all four groups (MANOVA, $\mathrm{p}<0.001$ ). Arm span to height ratio is also significantly different across groups (MANOVA, $\mathrm{p}<0.001$ ). Male Army recruits have a larger average arm span to height ratio than MMA fighters, although arm span and height are both significantly higher in MMA fighters than Army recruits, male or female. Of the groups sampled, sex-specific data were available only for the Army recruits. Comparison using MANOVA finds that male Army recruits are significantly taller and have significantly wider arm span and larger arm span to height ratios than do female recruits (Table $2, \mathrm{p}<0.001$ ).

Table 2. Descriptive statistics for the study groups

\begin{tabular}{lcccccccccc}
\hline & & \multicolumn{3}{c}{ HEIGHT $(\mathbf{c m})$} & \multicolumn{4}{c}{ ARM SPAN $(\mathbf{c m})$} & \multicolumn{3}{c}{ AHR } \\
\cline { 3 - 11 } Group & $\mathbf{N}$ & Mean & SD & CV & Mean & SD & CV & Mean & SD & CV \\
\hline Basketball & 2,990 & 195.90 & 9.09 & 4.64 & 206.69 & 10.79 & 5.22 & 1.06 & 0.03 & 2.81 \\
MMA & 1,284 & 178.35 & 8.51 & 4.77 & 182.55 & 10.22 & 5.60 & 1.02 & 0.03 & 2.65 \\
USA (M) & 4,082 & 175.62 & 6.86 & 3.90 & 181.42 & 8.46 & 4.67 & 1.03 & 0.03 & 2.65 \\
USA (F) & 1,986 & 162.85 & 6.42 & 3.94 & 166.03 & 8.30 & 5.00 & 1.02 & 0.03 & 2.87 \\
COMBINED & $\mathbf{1 0 , 3 4 2}$ & $\mathbf{1 7 9 . 3 7}$ & $\mathbf{1 4 . 0 2}$ & $\mathbf{7 . 8 1}$ & $\mathbf{1 8 5 . 9 1}$ & $\mathbf{1 7 . 2 7}$ & $\mathbf{9 . 2 9}$ & $\mathbf{1 . 0 4}$ & $\mathbf{0 . 0 3}$ & $\mathbf{3 . 0 3}$ \\
\hline
\end{tabular}

Note. Abbreviations as follows: MMA is mixed martial arts, USA is United states Army, M is male, F is female, AHR is arm span to height ratio, N is sample size, SD is standard deviation, CV is coefficient of variation.

Arm span is significantly correlated with height $(r=0.95$, $\mathrm{p}<0.0001)$ and height significantly predicts arm $\operatorname{span}\left(\mathrm{R}^{2}=0.90\right.$, $\mathrm{p}<0.0001$ ) in a pooled sample including all four groups (Figure 1). Bivariate regression between arm span and height produces slightly different regression lines with different intercepts for each group (Table 3). However, comparing the regression slopes between basketball players, MMA fighters, and Army recruits finds no significant difference (ANCOVA, $\mathrm{p}=0.262$ ). The relationship between arm span and height is not isometric, but rather reflects an allometric effect: taller people have relatively wider arm spans than do shorter people. In all four groups, arm span is on average greater than height and is tightly constrained, with arm span to height ratio ranging from 0.94 to $1.12(\mathrm{CV}=3.03)$.

Table 3. Results of the linear regression analysis

\begin{tabular}{lcccc}
\hline Sample & Intercept & Slope $^{\mathbf{a}}$ & $\mathbf{R}^{\mathbf{2}}$ & P-value \\
\hline Basketball & 10.80 & 1.00 & 0.71 & $<2.2 \mathrm{e}-16$ \\
MMA & -6.42 & 1.06 & 0.78 & $<2.2 \mathrm{e}-16$ \\
USA (M) & 2.94 & 1.02 & 0.68 & $<2.2 \mathrm{e}-16$ \\
USA (F) & -6.36 & 1.06 & 0.67 & $<2.2 \mathrm{e}-16$ \\
COMBINED & $\mathbf{- 2 4 . 1 9}$ & $\mathbf{1 . 1 7}$ & $\mathbf{0 . 9 0}$ & $<2.2 \mathrm{e}-16$ \\
\hline
\end{tabular}

Note. Abbreviations as follows: MMA is mixed martial arts, USA is United States Army, M is male, $\mathrm{F}$ is female, $\mathrm{R}^{2}$ is the coefficient of determination.

a Slopes are not significantly different between groups (ANCOVA, $p=0.262$ ).

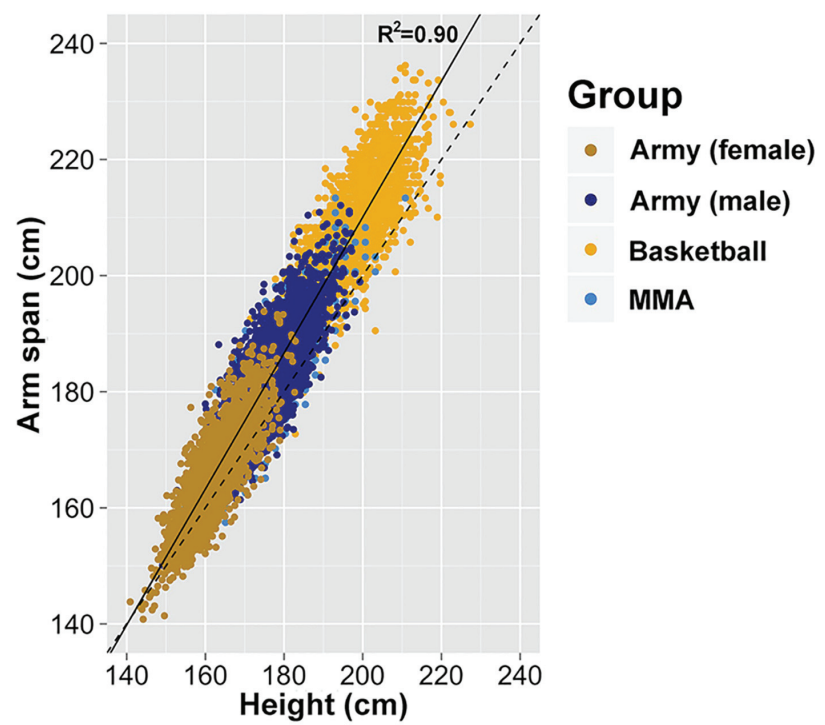

Legend: The solid line represents the regression line $(y=1.17 x-24.19)$ and the dashed line represents the 1:1 line $(y=x)$. Arm span and height are significantly correlated across groups $(r=0.95, p<0.001)$, and height significantly predicts arm $\operatorname{span}\left(R^{2}=0.90, p<0.001\right)$.

Figure 1. Linear regression comparing arm span and height across all four groups sampled 
Linear regression finds that arm span to height ratio significantly predicts athletic success in NBA players $\left(\mathrm{R}^{2}=0.007\right.$, $\mathrm{p}=0.016)$ and MMA fighters $\left(\mathrm{R}^{2}=0.008, \mathrm{p}=0.0007\right.$, Figure 2$)$.
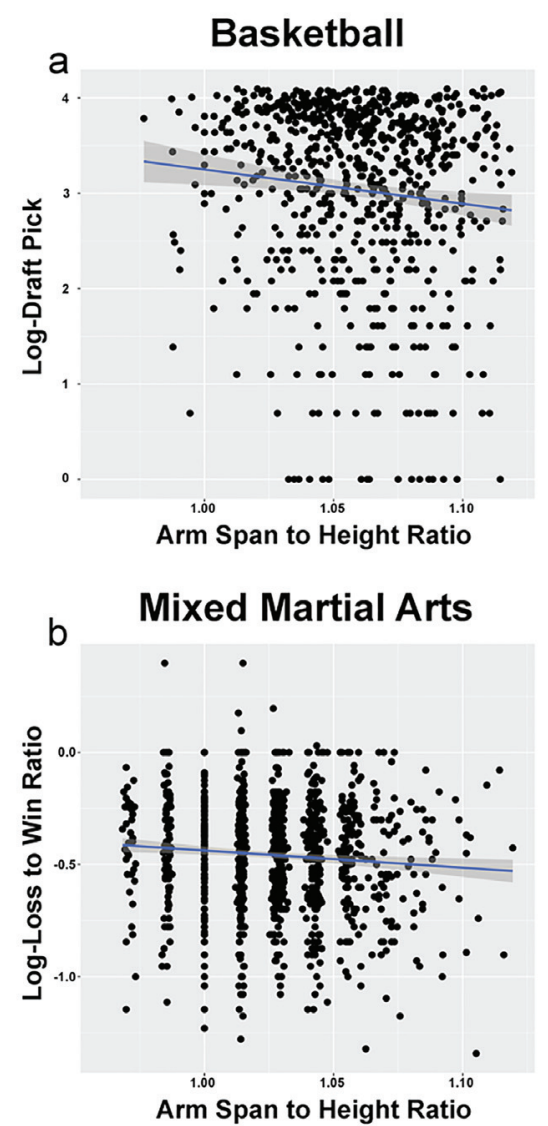

Legend: a) Arm span to height ratio and log-transformed draft pick in NBA players, b) Arm span to height ratio and log-transformed loss to win ratio in MMA fighters. Larger arm span to height ratio is significantly associated with a lower draft pick (a) or lower loss to win ratio (b). See text for definitions of athletic success.

Figure 2. Linear regression comparing arm span to height ratio with measures of athletic success

To further explore performance at the very highest level, we chose the top five athletes in each sport sampled, using loss to win ratio for MMA, and rankings by Sports Illustrated 2018 (Golliver \& Mahoney, 2017) for the NBA, and highlighted their distribution around the regression line (Figure 3). Four of the top five NBA players (LeBron James, Kevin Durant,
Kawhi Leonard, and James Harden) sit above the regression line of arm span to height, while Stephen Curry sits below the regression line for people sampled here. Among MMA fighters, Jon Jones and Jimmie Rivera sit above the regression line, while Daniel Cormier, Cris Cyborg, and Tom Duquesnoy sit below the regression line.

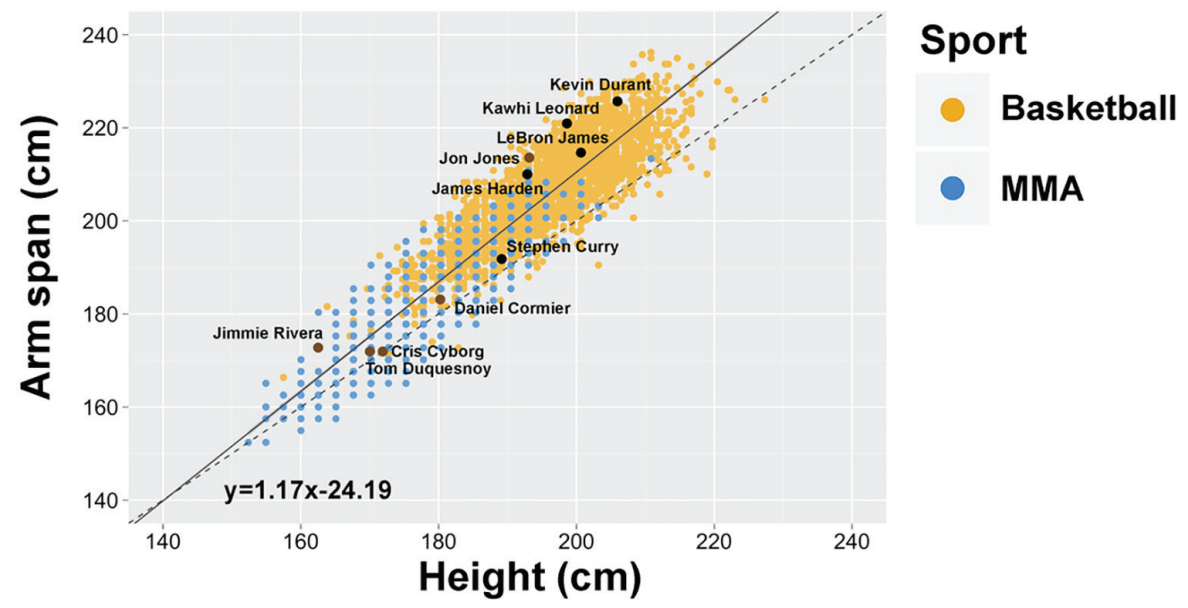

Legend: See methods for elaboration on choice of top athletes. The solid line represents the regression line $(y=1.17 x-24.19)$ and the dashed line represents the 1:1 line. Height significantly predicts arm span in athletes sampled $\left(R^{2}=0.85, p<0.001\right)$.

Figure 3. Bivariate plot with linear regression comparing arm span and height in basketball players and MMA fighters, with the top five athletes in each sport highlighted and labeled (black for basketball and brown for MMA) 


\section{Discussion}

From an evolutionary perspective, variation in limb proportions is key to variation in locomotion across our primate relatives and in mammals more broadly (Jungers, 1985). Humans are highly unusual compared to other great apes because of our ability to stand and walk upright efficiently (Jungers, 1985). Compared to our fossilized ancestors who lived 4 million years ago, humans today are taller (on average) and have relatively longer legs and shorter arms (Ruff, 2002). Modern human limb proportions and stature evolved by 1.5 million years ago in Homo erectus (Ruff, 2002; Walker \& Leakey, 1993) along with the ability to walk bipedally as efficiently as modern people (Lordkipanidze et al., 2007). One of the phenotypic correlates of bipedalism is the decoupling of fore - and hindlimb proportions, such that arm span in humans is more independent from leg length than in other nonape primates (Young et al., 2010). The archaeological record indicates that human height was fairly stable from 100,000 to 50,000 years ago and has since experienced a small decrease in average stature (Formicola \& Giannecchini, 1999; Ruff et al., 2002). Humans today are highly variable in body size and shape, and the relationship between stature and arm span has been found to vary between human populations due to both environmental and genetic factors (Popović et al., 2015; Ruff, 2002). As a global average, arm span generally exceeds stature, although in some populations arm span is very close and sometimes even less than stature (Popović et al., 2015; Stulp \& Barrett, 2016).

Our large scale analysis of data representing populations of diverse ancestry reveals that arm span and height are tightly correlated. This observation accords with those of previous studies that relied on smaller samples but found comparable correlations ( $r=0.73$ to 0.89 ) between arm span and height (Reeves et al., 1996) as well as comparable arm span to height ratios (1.00 to 1.04) in adolescents (Reeves et al., 1996), elite MMA fighters (Kirk, 2016), and basketball players (Gryko et al., 2018). Human height is a complex trait, with dozens of genes implicated in normal height variation (e.g., Yang et al., 2010). The significant correlation between arm span and height strongly suggests that this covariation results from pleiotropic effects.

We also find that the four categories (basketball players, MMA fighters, and male and female Army recruits) differ significantly from each other in terms of arm span, height, and arm span to height ratio. Basketball players are, on average, significantly taller and have significantly wider arm span and a larger arm span to height ratio than MMA fighters and Army recruits. Mixed martial arts fighters, while shorter than elite basketball players, are significantly taller than non-athletes (represented here by both male and female Army recruits, analyzed separately), with a significantly wider average arm span. Given the strong evidence of a positive allometric effect, in which arm span to height ratio increases with height, these differences between the four groups are more likely explained by differences in height, with differences in arm span increasing in an allometric fashion.

This allometric relationship between arm span and height is likely driven by the positive allometry of the distal limb elements specifically. Previous studies have shown that the ulna and radius of the arms exhibit positive allometry, while proximal limb segments exhibit isometry, or slight negative allometry with stature (Auerbach \& Sylvester, 2011). This means that taller individuals have lower arms that are proportionally longer, relative to overall arm length, than do shorter individuals. Long fingers, which have also been found to be associated with taller individuals (Meadows \& Jantz, 1992), likely also contribute to the allometric relationship observed here. Using the ANSUR data (Gordon et al., 2014), we compared hand length and stature and found that these traits are significantly correlated in men $(\mathrm{r}=0.67, \mathrm{p}<0.001)$ and women $(\mathrm{r}=0.65, \mathrm{p}<0.001)$.

In regards to athletic success, we find a significant association between athletic success and arm span to height ratio in our sample, as defined by draft pick in the NBA, or loss to win ratio for MMA fighters. Among these professional athletes, individuals with larger arm span to height ratios are significantly more likely to achieve athletic success as measured by these metrics. For MMA fighters in particular, these results contradict smaller studies that have used alternate metrics of athletic success, such as rankings (Kirk, 2016). Informal studies have previously reported that NBA players with the largest arm span to height ratios are not the 'best' players (Zetterberg \& Hallmark, 2011). We also find that some of the highest ranked and most recognizable athletes have body size proportions that sit below the regression line, moreso in MMA than the NBA.

Overall, successful athletes do tend to have a significantly wider arm span relative to their height, but these proportions are not outside the expected range of normal human variation. Having a larger arm span to height ratio may be significantly associated with athletic success, but it is widely recognized that athletes are successful due to a range of genetic, developmental, behavioral, environmental, and socioeconomic factors (Huffman \& Cooper, 2012; Lindner et al., 1991). Minor variation in body proportions, especially at the most elite levels, is unlikely to be predictive of athletic success, but does seem to confer a slight advantage.

\section{Acknowledgements}

We would like to thank Peter Kloess, Joshua Carlson, Catherine Taylor, and Andrew Weitz for helpful feedback and discussion during the course of this project. We would also like to thank the one anonymous reviewer and Editor-in-Chief Bojan Mašanović for their helpful comments that greatly improved this manuscript. TAM was funded by the Human Evolution Research Center at the University of California Berkeley during the course of this study. TAM wrote the manuscript, MFB contributed to writing and editing the manuscript. LJH directed the larger project in which this work was done and edited the manuscript. All authors contributed to the intellectual content, context, and interpretation of this study. All data are freely available from DraftExpress, FightMetric, and ANSUR II (2014).

\section{Conflict of Interest}

The authors declare that there are no conflicts of interest.

Received: 21 April 2018| Accepted: 01 June 2018| Published: 13 July 2018

\section{References}

Ackland, T.R., Schreiner, A.B., \& Kerr, D.A. (1997). Absolute size and proportionality characteristics of World Championship female basketball players. Journal of Sports Sciences, 15(5), 485-490.

Auerbach, B.M., \& Sylvester, A.D. (2011). Allometry and apparent paradoxes in human limb proportions: implications for scaling factors. American Journal of Physical Anthropology, 144(3), 382-391. doi: 10.1002/ ajpa. 21418

Beamon, K., \& Bell, P.A. (2002). "Going Pro": the deferential effects of high aspirations for a professional sports career on African-American student athletes and White student athletes. Race and Society, 5(2), 179-191. doi: 10.1016/j.racsoc.2004.01.006

Cureton Jr., T.K., \& Hunsicker, P. (1941). Body Build as a Framework of Reference for Interpreting Physical Fitness and Athletic Performance, Re- 
search Quarterly. American Association for Health, Physical Education and Recreation, 12(2), 301-330. doi: 10.1080/10671188.1941.10624688

Davies, J.H., \& Cheetham, T. (2014). Investigation and management of tal stature. Archives of Disease Childhood, 99, 772-777. doi: 10.1136/archdischild-2013-304830

Formicola, V., \& Giannecchini, M. (1999). Evolutionary trends of stature in Upper Paleolithic and Mesolithic Europe. Journal of Human Evolution 36(3), 319-333. doi: 10.1006/jhev.1998.0270

Golliver, B., \& Mahoney, R. (2017, September). Top 100 NBA Players of 2018. Sports Illustrated. Retrieved March 2018 from https://www.si.com nba/2017/09/14/nba-top-100-players-2018-lebron-james-stephencurry-kevin-durant.

Gordon, C.C., Blackwell, C.L., Bradtmiller, B., Parham, J.L., Barrientos, P. Paquette, S.P., Corner, B.D., Carson, J.M., Venezia, J.C., Rockwell, B.M., \& Mucher, M. (2014). 2012 Anthropometric survey of US Army personnel: methods and summary statistics (No. NATICK/TR-15/007). Army Natick Soldier Research Development and Engineering Center MA. Retrieved June, 2017, from http://www.dtic.mil/dtic/tr/fulltext/u2/a611869.pdf

Gryko, K., Kopiczko, A., Mikołajec, K., Stasny, P., \& Musalek, M. (2018). Anthropometric variables and somatotype of young and professional male basketball players. Sports, 6(1):9. doi:10.3390/sports6010009

Harrell, F.E., \& Dupont, M.C. (2012). Package 'Hmisc'. R Foundation for Statis tical Computing. Retrieved February 2018, from https://cran.r-project. org/web/packages/Hmisc/Hmisc.pdf

Huffman, L.T., \& Cooper, C.G. (2012). I'm taking my talents to...an examination of hometown socio-economic status on the college-choice factors of football student-athletes at a southeastern university. Journal of Issues in Intercollegiate Athletics, 5, 225-246.

Jungers, W. L. (1985). Chapter 16-Body size and scaling of limb proportions in primates. Chapter taken from Size and Scaling in Primate Biology ISBN: 1489936491 Advances in Primatology (pp. 345-381).

Kirk, C. (2016). Does stature or wingspan length have a positive effect on competitor rankings or attainment of world title bouts in international and elite mixed martial arts? Sport Science Review, 5-6, 334-349. doi: 10.1515/ssr-2016-0018

Lindner, K.J., Johns, D.P., \& Butcher, J. (1991). Factors in withdrawal from youth sport: A proposed model. Journal of Sport Behavior, 14(1), 3-18.

Lordkipanidze, D., Jashashvili, T., Vekua, A., Ponce de León, M.S., Zollikofer C.P.E., Rightmire, G.P., Pontzer, H., Ferring, R., Oms, O., Tappen, M., Bukhsianidze, M., Agusti, J., Kahlke, R., Kiladze, G., Martinez-Navarro, B., Mouskhelishvili, A., Nioradze, M., \& Rook, L. (2007). Postcranial evidence from early Homo from Dmanisi, Georgia. Nature, 449, 305-310.

McCauley, J. (2018, April). NBA teams paying closer attention to players' wingspan. Los Angeles Times. Retrieved April 13, 2018 from http://www. latimes.com/sns-bc-bkn--nba-wingspan-fascination-20180410-story. html

Meadows, L., \& Jantz, R.L. (1992). Estimation of stature from metacarpal lengths. Journal of Forensic Sciences, 37(1), 147-154. doi: 10.1520/ JFS13222J

Miller, S.G. (2005). Ancient Greek Athletics. New Haven: Yale University.

Nadankutty, J., Lu, L.A., Liang, T.Y., Stephen, J.A., Anuar, M.A.R.K., Yusuf, Y.A (2014). Correlative study of wingspan (armspan) length and body length in students of SEGi University, Malaysia. Open Science Repository
Anthropology. doi:10.7392/openaccess.45011801

Norton, K., \& Olds, T. (2001). Morphological evolution of athletes over the 20th century. Sports Medicine, 31(11), 763-783.

Nwosu, B.U., \& Lee, M.M. (2008). Evaluation of short and tall stature in children. American Family Physician, 78(5), 597-604.

Popović, S., Bjelica, D., Tanase, G.D. \& Milasinovic, R. (2015). Body height and its estimation utilizing arm span measurements in Bosnian and Herzegovinian adults. Montenegrin Journal of Sports Science and Medicine, 4(1), 29-36.

R Core Team. (2015). R: a language and environment for statistical computing. R Foundation for Statistical Computing. Retrieved January 2018 from http://www.R-project.org/.

Rappold, G., Blum, W.F., Shavrikova, E.P., Crowe, B.J., Roeth, R., Quigley, C.A. Ross, J.L., \& Niesler, B. (2007). Genotypes and phenotypes in children with short stature: clinical indicators of SHOX haploinsufficiency. Journal of Medical Genetics, 44(5), 306-313.

Reeves, S.L., Varakamin, C., Henry, C.J.K. (1996). The relationship between arm-span measurements and height with special reference to gender and ethnicity. European Journal of Clinical Nutrition, 50, 398-400.

Revelle, W. (2015). The psych package - CRAN. $R$ Foundation for Statistical Computing. Retrieved January 2018 from https://cran.r-project.org/ web/packages/psych/psych.pdf

Ruff, C. (2002). Variation in human body size and shape. Annual Review of Anthropology, 31,211-232. doi: 10.1146/annurev.anthro.31.040402.085407

Sellers, R.M., \& Kuperminc, G.P. (1997). Goal discrepancy in African american male student-athletes' unrealistic expectations for careers in professional sports. Journal of Black Psychology, 23(1), 6-23. doi: $10.1177 / 00957984970231002$

Shea, B.T., \& Bailey, R.C. (1996). Allometry and adaptations of body proportions and stature in African pygmies. American Journal of Physical Anthropology, 100, 311-340.

Stulp, G., \& Barrett, L. (2016). Evolutionary perspectives on human height variation. Biological Reviews, 91(1), 206-234. doi: 10.1111/brv.12165

Torres-Unda, J., Zarrazquin, I., Gil, J., Ruiz, F., Irazusta, A., Kortajarena, M. Seco, J., \& Irazusta, J. (2013). Anthropometric, physiological and maturational characteristics in selected elite and non-elite male adolescent basketball players. Journal of Sports Sciences, 31(2), 196-203. doi: 10.1080/02640414.2012.725133

Yang, J., Benyamin, B., McEvoy, B.P., Gordon, S., Henders, A.K., Nyholt, D.R. Madden, P.A., Heath, A.C., Martin, N.G., Montgomery, G.W., Goddard, M.E., \& Visscher, P.M. (2010). Common SNPs explain a large proportion of the heritability for human height. Nature Genetics, 42(7), 565-569.

Young, N.M., Wagner, G.P., \& Hallgrímsson, B. (2010). Development and evolvability of human limbs. Proceedings of the National Academy of Sciences, 107(8), 3400-3405.

Walker, A., \& Leakey, R. (1993). The Nariokotome Homo erectus Skeleton. Cambridge: Harvard University Press.

Wickham, H. (2009). ggplot2: Elegant Graphics for Data Analysis. Houston: Springer.

Zetterberg, B., \& Hallmark, J. (2011, September). NBA Basketball: What Qualifies as a "Freakish" Wingspan in the League? Retrieved April 2018 from http://bleacherreport.com/articles/864549-nba-basketball-what-qualifies-as-a-freakish-wingspan-in-the-league 